\title{
AMPA receptors control fear extinction through an Arc-dependent mechanism
}

\author{
Simon Trent, ${ }^{1}$ Philip Barnes, ${ }^{2}$ Jeremy Hall, ${ }^{1,3}$ and Kerrie L. Thomas ${ }^{1,2}$ \\ ${ }^{1}$ Neuroscience and Mental Health Research Institute, Cardiff University, Haydn Ellis Building, Cardiff CF24 4HQ, United Kingdom; \\ ${ }^{2}$ Cardiff School of Biosciences, Cardiff University, Park Place, Cardiff CF10 3AX, United Kingdom; ${ }^{3}$ MRC Centre for Neuropsychiatric \\ Genetics and Genomics, Haydn Ellis Building, Cardiff University, Cardiff CF24 4HQ, United Kingdom
}

\begin{abstract}
Activity-regulated cytoskeleton-associated protein (Arc) supports fear memory through synaptic plasticity events requiring actin cytoskeleton rearrangements. We have previously shown that reducing hippocampal Arc levels through antisense knockdown leads to the premature extinction of contextual fear. Here we show that the AMPA receptor antagonist CNQX elevates hippocampal Arc levels during extinction and blocks extinction that can be rescued by reducing Arc. Increasing Arc levels with CNQX also overcomes the actin-destabilizing properties of cytochalasin D and promotes extinction. Therefore, extinction is dependent on AMPA-mediated reductions of Arc via a mechanism consistent with a role for Arc in stabilizing the actin cytoskeleton to constrain extinction.
\end{abstract}

[Supplemental material is available for this article.]

Activity-regulated cytoskeleton-associated protein (Arc) plays a key role in balancing both synaptic and structural plasticity (Peebles et al. 2010). Arc supports the maintenance of longterm potentiation (LTP) by stabilizing the actin cytoskeleton (Messaoudi et al. 2007) and supports mGluR-dependent longterm depression (LTD) and homeostatic plasticity by regulating AMPAR endocytosis (Chowdhury et al. 2006; Plath et al. 2006; Rial Verde et al. 2006; Shepherd et al. 2006; Park et al. 2008; Waung et al. 2008). Functionally, Arc activity in the hippocampus is required for the consolidation of spatial and contextual memories (Guzowski et al. 2000, 2001b).

We have recently shown Arc in the hippocampus plays an important role in the maintenance of conditioned fear memories (CFM) after recall (Trent et al. 2015). Specifically, we showed that knockdown of Arc levels in the hippocampus with targeted ASO cDNA (ARCASO) at retrieval resulted in a loss of conditioned fear responses. The ability to recover the memory at a later point indicated the ARCASO was not blocking the recall-dependent reconsolidation of memory, which predicts a persistent amnesia, but instead shows that that Arc was part of a molecular process that acts to constrain the extinction of the fear memory. Extinction is a learning process that involves the encoding of a new contingency when a conditioned stimulus (CS) no longer predicts an event (Pavlov 1927) and at recall, the extinction memory competes directly with the original excitatory memory resulting in the weakening of the behavioral conditioned response (CR) (Myers and Davis 2007). We also showed that Arc expression was greater under conditions of recall (a 2 min short recall session (SR)) that does not lead to extinction compared with another (a 10 min long recall session (LR)) that did. These data highlight the inverse correlation between Arc levels and extinction (Barnes and Thomas 2008). Furthermore, they suggest a key role for Arc in CFM extinction, alongside its well-established role of CFM consolidation, although the precise role for Arc in the two memory processes may differ.

\section{Corresponding author: ThomaskL5@cf.ac.uk}

Article is online at http://www.learnmem.org/cgi/doi/10.1101//m.045013. 117.
Here we have investigated the role of Arc in extinction further by using the AMPA/kainate receptor antagonist CNQX to increase hippocampal Arc protein levels. This approach leverages a previously characterized mechanism whereby AMPAR activity is known to negatively regulate activity-dependent Arc gene expression by decreasing the rate of $A r c$ gene transcription and reduce Arc protein levels (Rao et al. 2006). We hypothesize that ectopically increasing hippocampal Arc levels using CNQX after prolonged CFM would impair extinction. We also investigated a mechanism by which Arc may be acting. Extinction is impaired by the actindestabilizing agent cytochalasin $\mathrm{D}$ indicating that extinction is dependent on actin rearrangements (Fischer et al. 2004). It is also known that Arc is necessary for the synaptic plasticity mechanisms that rely on stabilizing actin dynamics (Messaoudi et al. 2007). Thus we predict that the direct role of Arc in controlling actin dynamics after recall would be demonstrated by a CNQXmediated rescue of extinction after destabilization of the actin network with cytochalasin D.

In a first experiment we used the AMPA/kainate receptor antagonist CNQX to test the hypothesis that the infusion of CNQX into the dorsal hippocampus immediately after LR would be able to prevent the extinction-associated reduction in Arc protein levels. Rats were cannulated and CNQX or PBS was infused directly into the hippocampus after SR or LR (see Supplemental Methods for details, (Izquierdo et al. 1993, 2000)). Extinction induced by a $10 \mathrm{~min}$ LR exposure to a fear-conditioned context (Fig. 1A) was correlated with a decrease in Arc protein in CA1 of PBS-infused animals (Fig. 1B), as we have observed before (Barnes and Thomas 2008). However, this decrease in Arc was prevented with the infusion of CNQX following extinction (Fig. 1B). Therefore, AMPA/kainate receptors regulate Arc levels in an activity-dependent manner in vivo, and in extinction, CNQX treatment prevents the reduction in Arc levels.

(C) 2017 Trent et al. This article is distributed exclusively by Cold Spring Harbor Laboratory Press for the first 12 months after the full-issue publication date (see http://learnmem.cshlp.org/site/misc/terms.xhtml). After 12 months, it is available under a Creative Commons License (Attribution-NonCommercial 4.0 International), as described at http://creativecommons.org/licenses/by$\mathrm{nc} / 4.0 /$. 
A

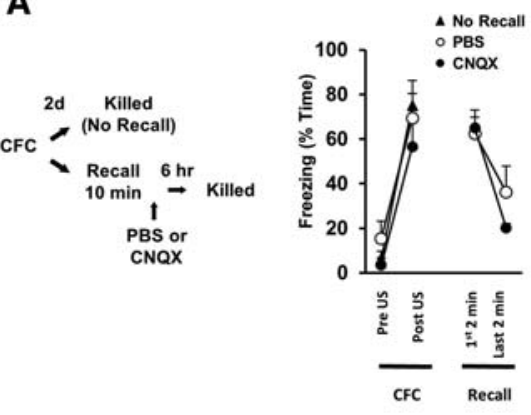

C

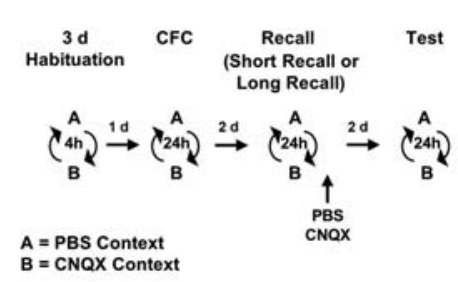

B

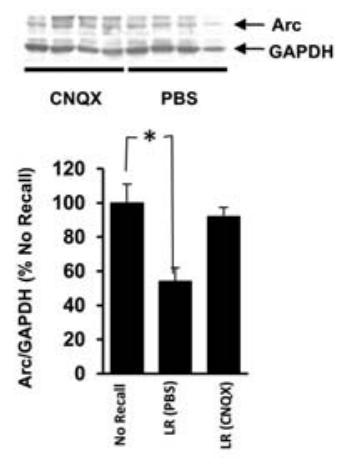

D

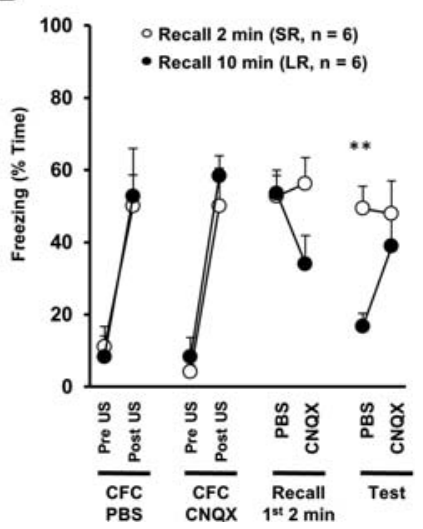

Figure 1. Hippocampal $C N Q X$ elevates Arc protein in CA1 during extinction training and impairs extinction of contextual fear memory. (A) Rats $(n=21)$ received a single CFC trial. Immediately after a prolonged 10 min exposure to the conditioned context $2 \mathrm{~d}$ later, groups of rats received PBS $(n=6)$ or CNQX $(n=5)$. There was no difference in the decrement in the fear response measured between the first and last 2 min of extinction training between the PBS and CNQX groups. (B) There was a significant effect of CNQX on CA1 Arc $6 \mathrm{~h}$ after extinction training $\left(F_{(2,15)}=8.003, P=0.004\right.$, ANOVA). LR $(P B S)=P B S$ infusion after $10 \mathrm{~min}$ long recall. $L R(C N Q X)=C N Q X$ infusion after 10 min long recall. Results are presented as the Mean \pm SEM. $\left(^{*}\right) P<0.01$, compared with No Recall group. (C) Rats $(n=12)$ received two nonreinforced extinction-training trials (context $\mathrm{A}$ and context $\mathrm{B}, 24 \mathrm{~h}$ apart) $2 \mathrm{~d}$ after CFC in the two distinct contexts (for either 2 min (short recall (SR) group, $n=6$ ) or $10 \mathrm{~min}$ (long recall (LR) group, $n=6$ )). Immediately after extinction they received either CNQX or PBS such that each rat was infused with PBS associated with one of the two conditioned contexts (Context A) and CNQX following exposure to the other context (Context B). The experiment was completely counterbalanced for the context associated with CNQX across the two groups and the order of PBS and CNQX infusions. (D) There was a significant effect on freezing behavior during CFC training trials and the first $2 \mathrm{~min}$ of recall $\left(F_{(2.996,29.956)}=21.474, P=0.000, \epsilon=0.599\right.$, repeated-measures ANOVA) with no Freezing $\times$ Group interaction $\left(F_{(2.996,29.956)}=1.242, \quad P=0.312, \quad \epsilon=0.599\right.$, repeated-measures ANOVA). For the LR group there was a significant difference between the first and last $2 \mathrm{~min}$ of the recall session $\left(F_{(1,10)}=8.449, P=0.016\right.$, repeated-measures ANOVA), but no Freezing $\times$ Context interaction $\left(F_{(1,10)}=1.976, P=0.190\right.$, repeated-measures ANOVA, data not shown). This indicates within-session extinction in both Context A and B. In addition, CNQX did not result in any sensorimotor changes apparent to observation of the rats' behavior. During the LTM test $3 \mathrm{~d}$ later, there were no differences between the robust levels of conditioned freezing behavior in the SR rats in the CNQX and PBS associated contexts. However, the rats in the LR group showed significantly lower conditioned responses in the PBS-associated context than the SR group indicating robust between-session extinction after prolonged conditioned stimulus exposure. There was no difference in freezing behavior between the LR and SR groups in the context associated with the CNQX infusions. Results are presented as the Mean \pm SEM. Behavioral data for the first 2 min of extinction training is shown only. $\left.{ }^{* *}\right) P<0.01$.

Next, we used a behavioral procedure in which all rats were fear conditioned in two distinct contexts so that the two CFMs could be separately retrieved and extinguished by LR, one associated with CNQX treatment and the other not. A separate group of rats underwent the same procedure but using a SR session which does not produce extinction. This protocol provides a powerful method of investigating the effects of CNQX on extinction and memory stability after recall and to determine whether CNQX selectively impacted on a recalled memory (Fig. 1C). Rats were fear

conditioned to two different contexts (A and $\mathrm{B}$ ) by presenting a short unsignaled footshock in each of the contexts $2 \mathrm{~min}$ into a 3 min conditioning trial on consecutive days. The following day, rats underwent extinction training whereby each rat simply received either a 2 min exposure to each context $24 \mathrm{~h}$ apart (no extinction, SR group) or for $10 \mathrm{~min}$ to each context (extinction training, LR group). CNQX or PBS were infused into the dorsal hippocampus of each rat immediately after the recall sessions in a counterbalanced way such that each rat received $\mathrm{CNQX}$ following exposure to one of the contexts and PBS after exposure to the other context.

All rats discriminately conditioned to both contexts and showed robust CFM during the first 2 min of the extinction training (Fig. 1D). CNQX had no effect on CFM in the SR group measured during a test session $2 \mathrm{~d}$ later. However, under the key conditions of extinction (LR), high levels of freezing behavior were observed when the LR rats were reexposed to the CNQX-associated context, consistent with $\mathrm{CNQX}$ blocking the consolidation of extinction (Fig. 1D). Notably, CNQX did not result in any sensorimotor impairment apparent during observation of the rats' behavior. Thus hippocampal CNQX has no effect on CFM stability associated with SR that does not lead to extinction, but it prevented the extinction of CFM caused by prolonged context exposure, LR. Furthermore, the blockade of extinction by CNQX is selective for the recalled fear memory because reduced freezing at test shows intact extinction of the memory recalled in Context A (PBSassociated) either $24 \mathrm{~h}$ before or after. Therefore, these results show that hippocampal infusions of CNQX that are associated with the maintenance of higher Arc levels, also results in an impairment of extinction after LR.

We next investigated whether CNQX-mediated extinction blockade acts specifically by maintaining elevated Arc levels. This was determined by investigating whether the CNQX-induced block on extinction was overcome by reduction of Arc levels with ARCASO. We have previously shown that intrahippocampal ARCASO administered $1.5 \mathrm{~h}$ before recall reduces Arc levels in CA1 (Trent et al. 2015). During a standard single contextual fear conditioning (CFC) paradigm, rats received intrahippocampal infusions of either ARCASO or ARCMSO, $1.5 \mathrm{~h}$ before a $10 \mathrm{~min}$ reexposure to the conditioned context. This was followed by the immediate infusion of CNQX and subsequent test sessions 2 and $21 \mathrm{~d}$ later (LTM1 and 2). CNQX blocked extinction of the CFM in control animals receiving ARCMSO, replicating the findings from the two-context paradigm (see Fig. 2 and Fig. 1D). However, the CNQX-induced block 


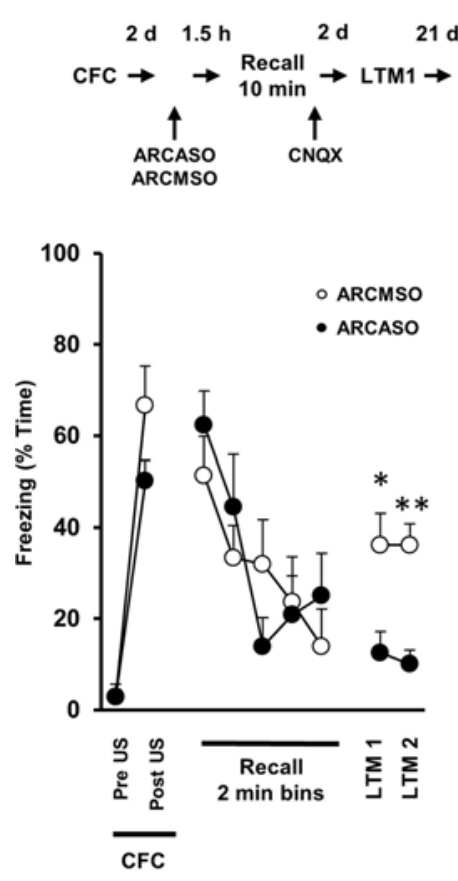

Figure 2. Intrahippocampal ARCASO rescues extinction after CNQX. Two days after CFC groups of rats received either ARCASO $(n=6)$ or ARCMSO $(n=6) 90$ min prior to 10 min nonreinforced recall and all animals received CNQX immediately afterward. Fear memory was tested after $2 \mathrm{~d}$ (LTM 1) and $23 \mathrm{~d}$ (LTM 2). There was no effect of Group on CFC $\left(F_{(1,10)}=4.086, P=0.071\right.$, repeated-measures ANOVA) or conditioned freezing during the recall $\left(F_{(3.009,30.093)}=2.44\right.$, $P=0.083$, repeated-measures ANOVA) indicating that both ARCASO and ARCMSO groups showed the same within-session extinction behavior $\left(F_{(3.009,30.093)}=14.573, P=0.000\right.$, repeated-measures ANOVA). During the LTM tests, extinction was only observed in the ARCASO group while in comparison the ARCMSO group showed higher conditioned freezing behavior $\left(F_{(1,9)}=17.918, P=0.002\right.$, Group between-subjects contrast, repeated-measures ANOVA. NB: One rat was excluded from this analysis because it died between LTM 1 and LTM 2). Results are presented as the Mean \pm SEM. Behavioral data for 2 min bins during recall is shown. $\left({ }^{*}\right) P<0.05\left({ }^{* *}\right) P<0.01$ compared with ARCMSO.

on extinction was rescued in animals given ARCASO (Fig. 2), demonstrating that the pharmacological blockade of AMPA/kainate receptors with CNQX prevents extinction though the specific downstream regulation of Arc levels.

Previous studies using direct infusions of cytochalasin D have shown that hippocampal actin rearrangements are required for the extinction of context-dependent fear (Fischer et al. 2004). We therefore next investigated whether increasing Arc levels with CNQX could rescue the effects of cytochalasin D treatment on extinction. We first confirm that intrahippocampal infusion of cytochalasin D immediately before LR specifically prevented the reduction in conditioned fear as tested at LTM1, indicating impaired consolidation of extinction (Fig. 3A). Next, we confirmed that CNQX immediately after LR attenuated the extinction in animals trained with a single CFM (Context A, Ctx A) (Fig. 3B), in line with our previous findings. We then determined the effect of CNQX given at the end of extinction training in animals treated with cytochalasin $\mathrm{D}$. The results showed that administration of CNQX, which we have shown increases Arc levels (Fig. 1B), rescued the loss of extinction memory seen after cytochalasin D treatment (Fig. 3B). These results suggest that extinction is dependent on the coordinated rearrangements of the actin cytoskeleton associated with LR acting through AMPA/kainate receptor- and Arc-dependent mechanisms.
Here we have shown the AMPA/kainate receptor antagonist CNQX maintains elevated levels of hippocampal Arc during extinction training and blocks the consolidation of extinction. We confirm that CNQX acts through elevated Arc levels during

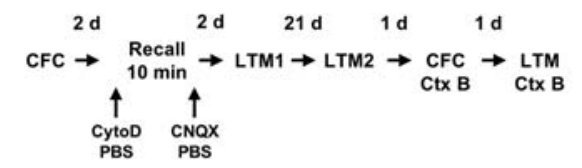

A
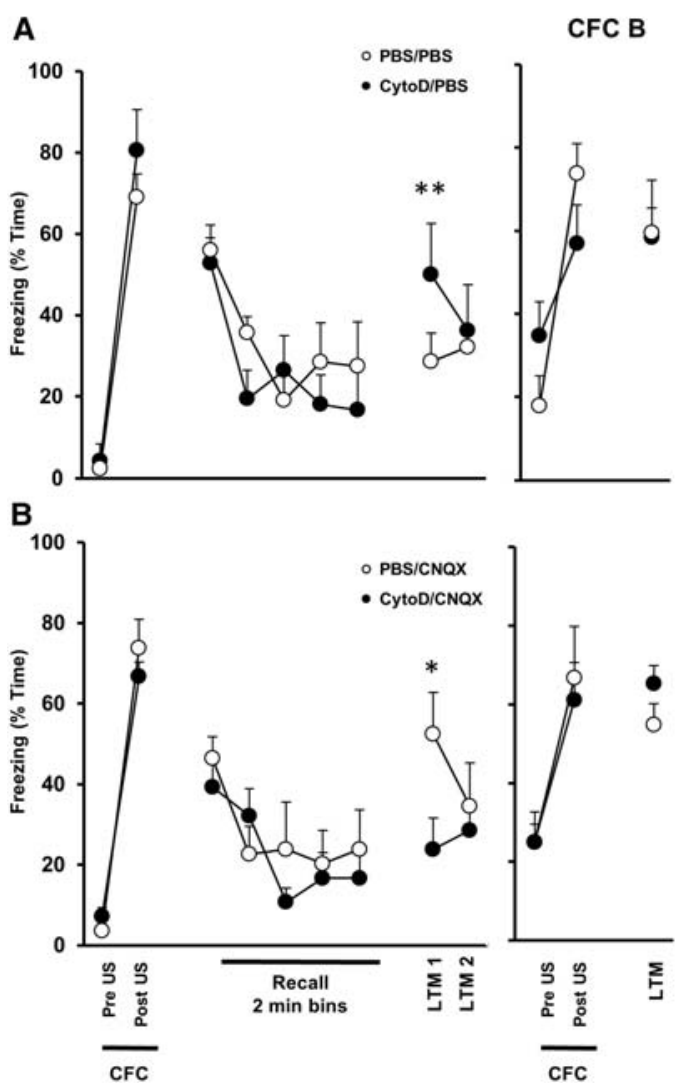

Figure 3. Infusions of $\mathrm{CNQX}$ into the hippocampus overcomes the extinction deficit caused by cytochalasin D. (A) Cytochalasin D (CytoD) infusion into the dorsal hippocampus prior to extinction training (10 min exposure to the conditioned context) had no effect on withinsession extinction compared with PBS-infused rats $\left(F_{(2.810,30.914)}=\right.$ $0.430, P=0.519, \epsilon=0.703$, repeated-measures ANOVA, $n=6 / 7$ per group). CytoD impaired the reduction in conditioned freezing at the LTM1 retrieval test $2 \mathrm{~d}$ after extinction training $\left(F_{(1,6)}=34.232, P=\right.$ 0.002 , repeated-measures ANOVA) but not at LTM2, 23 d later. All rats showed successful CFC and LTM in a new context (context B) subsequently (Conditioning, $F_{(1.935,21.317)}=15.478, P=0.000, \epsilon=0.969$; Conditioning $\times$ Group interaction, $F_{(1.935,21.317)}=2.513, P=0.104, \epsilon=$ 0.969 , repeated-measures ANOVAs). $\left({ }^{* *}\right) P<0.01$ freezing behavior of CytoD/PBS at LTM1 compared with last 2 min of Recall. (B) In a separate cohort of rats, CytoD again prevented between-session extinction assessed at LTM1 but not LTM2, with no effect on within-session extinction (Training $\times$ Group interaction, $F_{(2.954,35.451)}=2.513, P=0.104, \epsilon=0.739$, repeated-measures ANOVA, $n=7$ per group). Infusion of CNQX immediately after extinction training rescued the deficit in extinction recall tests LTM1 (Test $\times$ Group interaction, $F_{(1,12)}=7.616, P=0$. 017, repeated-measures ANOVA). All rats showed successful CFC and LTM in a new context (context $B$ ) subsequently (Conditioning, $F_{(1.822,20.045)}=$ 20.624, $P=0.000, \epsilon=0.968$; Conditioning $\times$ Group interaction, $F_{(1.822,20.045)}=0.901, P=0.363, \epsilon=0.968$, repeated-measures ANOVAs, $n=6 / 7$ per group). Results are presented as the Mean \pm SEM. Behavioral data for 2 min bins during recall is shown. $\left(^{*}\right) P<0.05$ compared with $\mathrm{PBS} / \mathrm{CNQX}$. 
extinction because reducing hippocampal Arc with targeted ARCASO infusions rescues extinction in the presence of CNQX. Therefore, the consolidation of extinction of CFM is dependent on hippocampal AMPA/kainate receptor activity (Dalton et al. 2008), with AMPA/kainate receptor-mediated decreases in Arc necessary for extinction consolidation. In addition, increasing Arc levels using CNQX overcomes the detrimental F-actin-destabilizing properties of cytochalasin $\mathrm{D}$ and thus promotes the consolidation of extinction.

In our extinction experiments, CNQX was given immediately after reexposure to the conditioned fear context, so its effect on extinction recall could not have been mediated by within-session reductions in conditioned response (CR) associated during LR (Myers and Davis 2007). Therefore, the high level of CR at subsequent tests following CNQX treatment indicates that CNQX specifically impairs the consolidation of extinction. The two-context fear memory experiment further shows the selectivity of the CNQX effect to the consolidation of extinction, as CNQX neither impaired the extinction of nonrecalled memories (i.e., extinction of the second PBS context $\pm 1 \mathrm{~d}$ was intact) or memories recalled for a short period of time (i.e., SR group). This demonstrates that the actions of CNQX on memory are recall- and activitydependent. The effects of CNQX are selective because AMPAR activation associated with recall is necessary for extinction but not the maintenance of an established memory, consistent with the previous observations of AMPAR antagonism in the amygdala (Ben Mamou et al. 2006).

Extinction training was associated with a decrease in Arc protein in the CA1 $6 \mathrm{~h}$ later and reductions in Arc were prevented by the AMPA/kainate receptor antagonist CNQX suggesting they are mediated by the receptor activity associated with LR and extinction. Previously we showed that a short 2 min recall of CFM does not change CA1 Arc protein levels (Barnes and Thomas 2008), while a long recall decreases Arc levels (Barnes and Thomas 2008) and ectopically reducing hippocampal Arc levels with ARCASO precipitated extinction (Trent et al. 2015). These data suggest that under native recall conditions Arc can act to constrain extinction. Indeed we now show that extinction impaired by CNQX and correlated with increased basal Arc levels, can be reinstated using ARCASO. The specificity of the ARCASO rescue effect is important given the broad pharmacological effects of CNQX on AMPA/kainate receptor-signaling (Stein et al. 1992; Malenka and Nicoll 1999; Armstrong and Gouaux 2000; Jin et al. 2003; Fleming and England 2010) and the subsequent complexity of signaling cascades downstream from these receptors that are relevant to plasticity, yet discrete from Arc itself (Rao et al. 2006; Rao and Finkbeiner 2007). Therefore, it appears that Arc is part of a pivotal mechanism that regulates fear extinction and that following retrieval of CFM, decreases in Arc protein in the hippocampus mediated through AMPA/kainate receptor activation are necessary for extinction.

Other studies have routinely reported elevated hippocampal Arc expression with the retrieval of hippocampal-dependent memories during single brief recall sessions (Guzowski et al. 2001a, 2006; Chia and Otto 2013) that are not associated with extinction (Trent et al. 2015). In contrast, following extinction, while mRNA levels are maintained to baseline levels (Trent et al. 2015), protein levels decrease below baseline (Fig. 1B; Barnes and Thomas 2008). This demonstrates the exquisite regulation of Arc levels by the exact conditions of recall. Since the activitydependent translation of Arc is under the tight control of nonsense-mediated mRNA decay (Giorgi et al. 2007), and there are independent mechanisms controlling the transcription and translation of Arc with synaptic activity (Panja et al. 2009), one may not expect to observe a strict stoichiometric concordance between measurable mRNA and protein levels (McIntyre et al. 2005).
Notwithstanding, there appears to be a tight inverse correlation between Arc expression and extinction. Since the dendritic targeting of Arc mRNA (Steward et al. 1998; Steward and Worley 2001) and spatially restricted translation are coupled via local synaptic activity (Farris et al. 2014), future investigations of the temporal and spatial regulation of Arc expression should reveal the precise contribution of $A r c$ to different plasticity and memory processes.

We confirmed a requirement of actin cytoskeleton rearrangements in the hippocampus in the extinction of CFM as shown by others (Fischer et al. 2004). Additionally, we observed that CNQX could fully restore the extinction impaired by cytochalasin D. These results suggest that increasing Arc levels using CNQX overcomes the F-actin-destabilizing properties of cytochalasin D and thus promotes the consolidation of extinction. This is consistent with a role for Arc in stabilizing the actin cytoskeleton, a role established for Arc in the maintenance of hippocampal LTP (Messaoudi et al. 2007).

Our results show two important contributions of Arc to extinction. First, that high levels of Arc-associated with recall constrain extinction and second that Arc plays a role in maintaining extinction by stabilizing the actin cytoskeleton in the rearrangements necessary for extinction. These roles may appear to be paradoxical. However, the resolution is very likely to reside in the coordinated functions of Arc at active, and potentially inactive synapses. A decrease in Arc expression and levels may contribute to the decreased stability of the cytoskeleton associated with activity (Lynch and Baudry 1984; Ouyang et al. 2005; Lynch et al. 2007; Rex et al. 2009). A reduction in Arc levels but not loss at active synapses would present a permissive environment in which other functions of Arc, for example, Arc-dependent AMPA receptor endocytosis required for synaptic and structural plasticity (Rial Verde et al. 2006; Shepherd et al. 2006; Waung et al. 2008; Peebles et al. 2010), can occur prior to the restabilization of the actin cytoskeletal partly orchestrated by Arc. A similar model for the coordinated depolymerization and polymerization of the actin cytoskeleton in memory consolidation has been suggested (Rudy 2014). Such a model would be consistent with data that show a time-limited labilization process that is required for memory updating and extinction associated with retrieval (Ben Mamou et al. 2006; Lee 2009). This scenario would also be consistent with the view of Arc being localized to inactive synapses (Okuno et al. 2012) and acting as an inverse tag for local plasticity events and acting to maintain information already stored in neuronal circuits. Thus, a persistent or mis-timed alteration in actin cytoskeleton is likely to disrupt memory consolidation and extinction processes associated with a specific experience.

In summary, these findings shed further light on the molecular and cellular mechanisms for the formation of extinction memory with Arc centrally placed to orchestrate the consolidation of extinction. We have observed that Arc gates extinction at recall, with high, sustained levels of Arc (through CNQX administration) constraining extinction and decreases in Arc (through Arc antisense administration) facilitating premature extinction. Moreover, our data expand the known molecular milieu within which Arc regulates extinction, placing AMPA and/or kainate receptors as an upstream mediator of extinction-relevant Arc levels and actin cytoskeleton rearrangements as a likely downstream effector role for Arc. Increased understanding of the molecular mechanisms involved in fear extinction can inform our understanding of human disorders of impaired fear extinction such as post-traumatic stress disorder, social phobia, panic disorder, and schizophrenia (Anderson and Insel 2006; Holt et al. 2009, 2012; Myers and Carlezon 2010; Myers et al. 2011). Moreover, Arc-associated pathways are implicated in increased susceptibility to neuropsychiatric disorders (Kirov et al. 2012; Fromer et al. 2014; Hall et al. 2015) and can be selectively targeted 
by drug compounds (Zhang et al. 2015). Therefore, Arc-directed treatments may represent a novel and tractable therapeutic strategy for ameliorating a key underlying molecular process in fear memory extinction.

\section{Acknowledgments}

This work was supported by the BBSRC (BB/C00583X), a Wellcome Trust Institutional Strategic Support Fund (504182), a Wellcome Trust Strategic Award (503147), and a Medical Research Council Centre Grant (GO801418).

Competing Interest Statement: The authors declare no competing financial interests.

\section{References}

Anderson KC, Insel TR. 2006. The promise of extinction research for the prevention and treatment of anxiety disorders. Biol Psychiatry 60: 319-321.

Armstrong N, Gouaux E. 2000. Mechanisms for activation and antagonism of an AMPA-sensitive glutamate receptor: crystal structures of the GluR2 ligand binding core. Neuron 28: 165-181.

Barnes P, Thomas KL. 2008. Proteolysis of proBDNF is a key regulator in the formation of memory. PLoS One 3: e3248.

Ben Mamou C, Gamache K, Nader K. 2006. NMDA receptors are critical for unleashing consolidated auditory fear memories. Nat Neurosci 9: $1237-1239$.

Chia C, Otto T. 2013. Hippocampal Arc (Arg3.1) expression is induced by memory recall and required for memory reconsolidation in trace fear conditioning. Neurobiol Learn Mem 106: 48-55.

Chowdhury S, Shepherd JD, Okuno H, Lyford G, Petralia RS, Plath N, Kuhl D, Huganir RL, Worley PF. 2006. Arc/Arg3.1 interacts with the endocytic machinery to regulate AMPA receptor trafficking. Neuron 52: 445-459.

Dalton GL, Wang YT, Floresco SB, Phillips AG. 2008. Disruption of AMPA receptor endocytosis impairs the extinction, but not acquisition of learned fear. Neuropsychopharmacology 33: 2416-2426.

Farris S, Lewandowski G, Cox CD, Steward O. 2014. Selective localization of arc mRNA in dendrites involves activity- and translation-dependent mRNA degradation. J Neurosci 34: 4481-4493.

Fischer A, Sananbenesi F, Schrick C, Spiess J, Radulovic J. 2004. Distinct roles of hippocampal de novo protein synthesis and actin rearrangement in extinction of contextual fear. J Neurosci 24 $1962-1966$.

Fleming JJ, England PM. 2010. Developing a complete pharmacology for AMPA receptors: a perspective on subtype-selective ligands. Bioorg Med Chem 18: 1381-1387.

Fromer M, Pocklington AJ, Kavanagh DH, Williams HJ, Dwyer S, Gormley P, Georgieva L, Rees E, Palta P, Ruderfer DM, et al. 2014. De novo mutations in schizophrenia implicate synaptic networks. Nature 506: $179-184$.

Giorgi C, Yeo GW, Stone ME, Katz DB, Burge C, Turrigiano G, Moore MJ. 2007. The EJC factor eIF4AIII modulates synaptic strength and neuronal protein expression. Cell 130: 179-191.

Guzowski JF, Lyford GL, Stevenson GD, Houston FP, McGaugh JL, Worley PF, Barnes CA. 2000. Inhibition of activity-dependent arc protein expression in the rat hippocampus impairs the maintenance of long-term potentiation and the consolidation of long-term memory. J Neurosci 20: 3993-4001.

Guzowski JF, McNaughton BL, Barnes CA, Worley PF. 2001a. Imaging neural activity with temporal and cellular resolution using FISH. Curr Opin Neurobiol 11: 579-584.

Guzowski JF, Setlow B, Wagner EK, McGaugh JL. 2001b. Experience-dependent gene expression in the rat hippocampus after spatial learning: a comparison of the immediate-early genes Arc, c-fos, and zif268. J Neurosci 21: 5089-5098.

Guzowski JF, Miyashita T, Chawla MK, Sanderson J, Maes LI, Houston FP, Lipa P, McNaughton BL, Worley PF, Barnes CA. 2006. Recent behavioral history modifies coupling between cell activity and Arc gene transcription in hippocampal CA1 neurons. Proc Natl Acad Sci 103: 1077-1082.

Hall J, Trent S, Thomas KL, O’Donovan MC, Owen MJ. 2015. Genetic risk for schizophrenia: convergence on synaptic pathways involved in plasticity. Biol Psychiatry 77: 52-58.

Holt DJ, Lebron-Milad K, Milad MR, Rauch SL, Pitman RK, Orr SP, Cassidy BS, Walsh JP, Goff DC. 2009. Extinction memory is impaired in schizophrenia. Biol Psychiatry 65: 455-463.

Holt DJ, Coombs G, Zeidan MA, Goff DC, Milad MR. 2012. Failure of neural responses to safety cues in schizophrenia. Arch Gen Psychiatry 69: 893-903.
Izquierdo I, Bianchin M, Silva MB, Zanatta MS, Walz R, Ruschel AC, Da Silva RC, Paczko N, Medina JH. 1993. CNQX infused into rat hippocampus or amygdala disrupts the expression of memory of two different tasks. Behav Neural Biol 59: 1-4.

Izquierdo LA, Barros DM, Ardenghi PG, Pereira P, Rodrigues C, Choi H, Medina JH, Izquierdo I. 2000. Different hippocampal molecular requirements for short- and long-term retrieval of one-trial avoidance learning. Behav Brain Res 111: 93-98.

Jin R, Banke TG, Mayer ML, Traynelis SF, Gouaux E. 2003. Structural basis for partial agonist action at ionotropic glutamate receptors. Nat Neurosci 6: 803-810.

Kirov G, Pocklington AJ, Holmans P, Ivanov D, Ikeda M, Ruderfer D, Moran J, Chambert K, Toncheva D, Georgieva L, et al. 2012. De novo $\mathrm{CNV}$ analysis implicates specific abnormalities of postsynaptic signalling complexes in the pathogenesis of schizophrenia. Mol Psychiatry 17: 142-153.

Lee JL. 2009. Reconsolidation: maintaining memory relevance. Trends Neurosci 32: 413-420.

Lynch G, Baudry M. 1984. The biochemistry of memory: a new and specific hypothesis. Science 224: 1057-1063.

Lynch G, Rex CS, Gall CM. 2007. LTP consolidation: substrates, explanatory power, and functional significance. Neuropharmacology $\mathbf{5 2}$ : $12-23$.

Malenka RC, Nicoll RA. 1999. Long-term potentiation--a decade of progress? Science 285: 1870-1874.

McIntyre CK, Miyashita T, Setlow B, Marjon KD, Steward O, Guzowski JF, McGaugh JL. 2005. Memory-influencing intra-basolateral amygdala drug infusions modulate expression of Arc protein in the hippocampus. Proc Natl Acad Sci 102: 10718-10723.

Messaoudi E, Kanhema T, Soulé J, Tiron A, Dagyte G, da Silva B, Bramham CR. 2007. Sustained Arc/Arg3.1 synthesis controls long-term potentiation consolidation through regulation of local actin polymerization in the dentate gyrus in vivo. J Neurosci 27: 10445-10455.

Myers KM, Carlezon WA Jr. 2010. Extinction of drug- and withdrawal-paired cues in animal models: relevance to the treatment of addiction. Neurosci Biobehav Rev 35: 285-302.

Myers KM, Davis M. 2007. Mechanisms of fear extinction. Mol Psychiatry 12: $120-150$.

Myers KM, Carlezon WA Jr, Davis M. 2011. Glutamate receptors in extinction and extinction-based therapies for psychiatric illness. Neuropsychopharmacology 36: 910.

Okuno H, Akashi K, Ishii Y, Yagishita-Kyo N, Suzuki K, Nonaka M, Kawashima T, Fujii H, Takemoto-Kimura S, Abe M, et al. 2012. Inverse synaptic tagging of inactive synapses via dynamic interaction of Arc/ Arg3.1 with CaMKIIß. Cell 149: 886-898.

Ouyang Y, Wong M, Capani F, Rensing N, Lee CS, Liu Q, Neusch C, Martone ME, Wu JY, Yamada K, et al. 2005. Transient decrease in F-actin may be necessary for translocation of proteins into dendritic spines. Eur J Neurosci 22: 2995-3005.

Panja D, Dagyte G, Bidinosti M, Wibrand K, Kristiansen AM, Sonenberg N, Bramham CR. 2009. Novel translational control in Arc-dependent long term potentiation consolidation in vivo. J Biol Chem 284: 31498-31511.

Park S, Park JM, Kim S, Kim JA, Shepherd JD, Smith-Hicks CL, Chowdhury S, Kaufmann W, Kuhl D, Ryazanov AG, et al. 2008. Elongation factor 2 and fragile $\mathrm{X}$ mental retardation protein control the dynamic translation of Arc/Arg3.1 essential for mGluR-LTD. Neuron 59: $70-83$.

Pavlov IP. 1927. Conditioned reflexes: an investigation of the physiological activity of the cerebral cortex. Ann Neurosci 17: 136-141.

Peebles CL, Yoo J, Thwin MT, Palop JJ, Noebels JL, Finkbeiner S. 2010. Arc regulates spine morphology and maintains network stability in vivo. Proc Natl Acad Sci 107: 18173-18178.

Plath N, Ohana O, Dammermann B, Errington ML, Schmitz D, Gross C, Mao X, Engelsberg A, Mahlke C, Welzl H, et al. 2006. Arc/Arg3.1 is essential for the consolidation of synaptic plasticity and memories. Neuron 52: 437-444.

Rao VR, Finkbeiner S. 2007. NMDA and AMPA receptors: old channels, new tricks. Trends Neurosci 30: 284-291.

Rao VR, Pintchovski SA, Chin J, Peebles CL, Mitra S, Finkbeiner S. 2006. AMPA receptors regulate transcription of the plasticity-related immediate-early gene Arc. Nat Neurosci 9: 887-895.

Rex CS, Chen LY, Sharma A, Liu J, Babayan AH, Gall CM, Lynch G. 2009. Different Rho GTPase-dependent signaling pathways initiate sequential steps in the consolidation of long-term potentiation. J Cell Biol 186: 85-97.

Rial Verde EM, Lee-Osbourne J, Worley PF, Malinow R, Cline HT. 2006. Increased expression of the immediate-early gene arc/arg3.1 reduces AMPA receptor-mediated synaptic transmission. Neuron 52: 461-474.

Rudy JW. 2014. Actin dynamics and the evolution of the memory trace. Brain Res. 1621: 17-28. 
Extinction control: AMPARs, Arc, and the actin cytoskeleton

Shepherd JD, Rumbaugh G, Wu J, Chowdhury S, Plath N, Kuhl D, Huganir RL, Worley PF. 2006. Arc/Arg3.1 mediates homeostatic synaptic scaling of AMPA receptors. Neuron 52: 475-484.

Stein E, Cox JA, Seeburg PH, Verdoorn TA. 1992. Complex pharmacological properties of recombinant $\alpha$-amino-3-hydroxy-5-methyl-4-isoxazole propionate receptor subtypes. Mol Pharmacol 42: 864-871.

Steward O, Worley PF. 2001. Selective targeting of newly synthesized Arc mRNA to active synapses requires NMDA receptor activation. Neuron 30: $227-240$.

Steward O, Wallace CS, Lyford GL, Worley PF. 1998. Synaptic activation causes the mRNA for the IEG Arc to localize selectively near activated postsynaptic sites on dendrites. Neuron 21: 741-751.
Trent S, Barnes P, Hall J, Thomas KL. 2015. Rescue of long-term memory after reconsolidation blockade. Nat Commun 6: 7897.

Waung MW, Pfeiffer BE, Nosyreva ED, Ronesi JA, Huber KM. 2008. Rapid translation of Arc/Arg3.1 selectively mediates mGluR-dependent LTD through persistent increases in AMPAR endocytosis rate. Neuron 59: $84-97$.

Zhang W, Wu J, Ward MD, Yang S, Chuang YA, Xiao M, Li R, Leahy DJ, Worley PF. 2015. Structural basis of arc binding to synaptic proteins: implications for cognitive disease. Neuron 86: 490-500.

Received January 14, 2017; accepted in revised form April 21, 2017. 


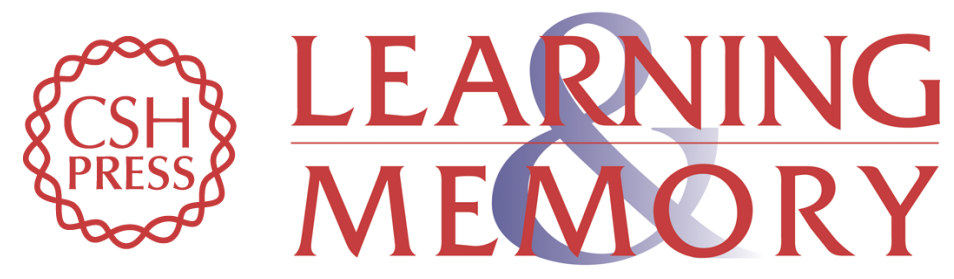

\section{AMPA receptors control fear extinction through an Arc-dependent mechanism}

Simon Trent, Philip Barnes, Jeremy Hall, et al.

Learn. Mem. 2017, 24:

Access the most recent version at doi:10.1101/Im.045013.117

\section{Supplemental http://learnmem.cshlp.org/content/suppl/2017/07/11/24.8.375.DC1 Material}

References This article cites 51 articles, 13 of which can be accessed free at: http://learnmem.cshlp.org/content/24/8/375.full.html\#ref-list-1

Creative This article is distributed exclusively by Cold Spring Harbor Laboratory Press for the Commons first 12 months after the full-issue publication date (see

License http://learnmem.cshlp.org/site/misc/terms.xhtml). After 12 months, it is available under a Creative Commons License (Attribution-NonCommercial 4.0 International), as described at http://creativecommons.org/licenses/by-nc/4.0/.

Email Alerting Receive free email alerts when new articles cite this article - sign up in the box at the Service top right corner of the article or click here. 